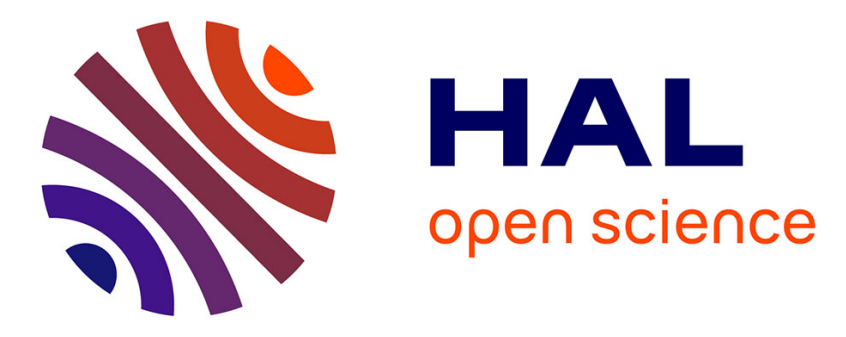

\title{
Second harmonic scattering from mass characterized 2D graphene oxide sheets
}

Isabelle Russier-Antoine, Hussein Fakhouri, Srestha Basu, Franck Bertorelle, Philippe Dugourd, Pierre-Francois Brevet, Prajitha Velayudhan, Sabu Thomas, Nandakumar Kalarikkal, Rodolphe Antoine

\section{To cite this version:}

Isabelle Russier-Antoine, Hussein Fakhouri, Srestha Basu, Franck Bertorelle, Philippe Dugourd, et al.. Second harmonic scattering from mass characterized 2D graphene oxide sheets. Chemical Communications, 2020, 56 (27), pp.3859-3862. 10.1039/D0CC00111B . hal-02569090

\section{HAL Id: hal-02569090 https://hal.science/hal-02569090}

Submitted on 5 Nov 2020

HAL is a multi-disciplinary open access archive for the deposit and dissemination of scientific research documents, whether they are published or not. The documents may come from teaching and research institutions in France or abroad, or from public or private research centers.
L'archive ouverte pluridisciplinaire HAL, est destinée au dépôt et à la diffusion de documents scientifiques de niveau recherche, publiés ou non, émanant des établissements d'enseignement et de recherche français ou étrangers, des laboratoires publics ou privés. 


\title{
Second Harmonic Scattering from Mass Characterized 2D Graphene Oxide Sheets
}

\author{
Isabelle Russier-Antoine, ${ }^{a}$ Hussein Fakhouri, ${ }^{\text {a Srestha Basu }},{ }^{a}$ Franck Bertorelle, ${ }^{\text {a Philippe }}$ \\ Dugourd, ${ }^{\text {a }}$ Pierre-François Brevet, ${ }^{\text {a }}$ Prajitha Velayudhan, ${ }^{\mathrm{b}}$ Sabu Thomas, ${ }^{\mathrm{b}}$ Nandakumar \\ Kalarikkal ${ }^{b, c}$ and Rodolphe Antoine*a
}

In this communication, we report the second harmonic scattering from mass characterized 2D graphene oxide sheets dispersed in an aqueous suspension, in the femtosecond regime at $800 \mathrm{~nm}$ laser excitation. Charge-detection mass-spectrometry, performing at the single sheet level, allows for an exhasutive molar mass distribution and thus concentration for these $2 \mathrm{D}$ nanomaterials samples. The orientation-averaged hyperpolarizability value is $(1,36+/-0,15) \times 10$ 25 esu as determined by the concentration-dependent harmonic scattering signal. In addition, the multi-photon excited fluorescence spectrum is characterized by a broad band in the visible range between 350 and $700 \mathrm{~nm}$ centered at about $500 \mathrm{~nm}$.

Two dimensional (2D) graphene has attracted considerable interest owing to its long-range $\pi$ conjugation, leading for instance to extraordinary electronic and optical properties. ${ }^{1,2}$ Also, large optical nonlinearities, including saturable absorption, four-wave mixing and two-photon absorption have been observed in pristine graphene. ${ }^{3,} 4$ However, solubility and processability of graphene come as the first issue for many perspective applications of graphene-based materials. Consequently, chemical functionalization of graphene has been focused on improving its solubility/processability in water and organic solvents. To date, the chemistry of graphene that has been reported mainly concerns the chemistry of graphene oxide $(\mathrm{GO})^{5}$ which has chemically reactive oxygen-containing groups including carboxylic acid and carbonyl groups at the edges of GO, epoxy and hydroxy groups on the basal planes. For GO, the unique chemical structure along with the heterogeneous electronic structure caused by the presence of $\mathrm{sp}^{2}$ and $\mathrm{sp}^{3}$ bonding confers intriguing properties that offer exciting prospects for the tailoring of NLO properties.6,7 Liu et al. studied harmonic generation (SHG). However, SHG from this material can be obtained by breaking the inversion symmetry via an external excitation such as electrical fields, currents or charges, with dopants or structure variations or by placing them onto a substrate. 9,10 The chemically reactive oxygen-containing groups in GO can thus be viewed as doping groups breaking the inversion symmetry in 2D graphene. In addition, the oxidation leading to disruption of infinite large $\mathrm{sp}^{2}$ domain induces the opening of bandgap that transforms the nonluminescent graphene into luminescent GO. ${ }^{11}$ Even if the origin of luminescence in $\mathrm{GO}$ is still under debate, ${ }^{12-14} \mathrm{GO}$ nanosheets also exhibit multiphoton luminescence, electroluminescence, and chemiluminescence. ${ }^{11}$

By an accurate characterization of the as-synthesized graphene oxide sheets, in particular with the measure of their molar mass, we have been able to determine for the first time their first hyperpolarizability at $800 \mathrm{~nm}$ laser excitation (see Fig. 1). The hyper Rayleigh scattering (HRS) technique examines concentration-dependent second harmonic generation (SHG) from colloidal dispersions to elucidate orientation-averaged hyperpolarizability $<\beta>$. Besides, polarization analysis investigates the nature of the SHG response. The benchmarking performed here permits to provide an absolute value of the hyperpolarizability for 2D graphene oxide sheets and can be used to understand the additional effect on NLO properties of targeting molecules ${ }^{15}$ or decorating nanoparticles ${ }^{16}$ on 2D graphene oxide platforms.

Institut Lumière Matière, UMR 5306 CNRS, Université Claude Bernard Lyon 1, Domaine Scientifique de La Doua, Batiment Kastler, 10 rue Ada Byron, 69622 Villeurbanne CEDEX, France.

International and Inter University Centre for Nanoscience and Nanotechnology and c. School of Pure and Applied Physics, Mahatma Gandhi, University, Kottayam 686560, Kerala, India.

† Footnotes relating to the title and/or authors should appear here.

Electronic Supplementary Information (ESI) available: [Experimental details. 2D charge-mass image, TEM, XPS analysis, UV-vis spectrum of graphene oxide samples. HRS signal vs concentration and light polarization]. See DOI: 10.1039/x0xx00000x

the nonlinear absorption in graphene oxide (GO) at visible wavelengths. ${ }^{8}$ In particular, they revealed that both two-photon absorption and excited state absorption were responsible for nonlinear absorption process of GO in the case of nanosecond and picosecond pulses.

Frequency conversion using 2D graphene based materials is a promising route for photonic materials due to their large optical nonlinearity. ${ }^{9}$ Yet, for an isolated monolayer graphene, its centrosymmetry prevents electric-dipole allowed second- 


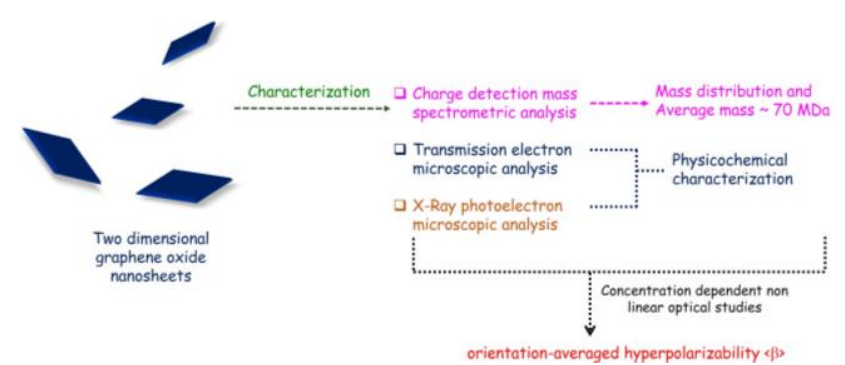

Figure 1: schematic showing the workflow used in this work. By an accurate physicochemical characterization of the as-synthesized graphene oxide sheets, in particular with the measure of their molar mass, concentration dependent nonlinear optical studies permit to determine their orientation-averaged hyperpolarizability value.

2D graphene oxide sheets were characterized by different techniques. We have obtained molar mass information for these 2D nanomaterials samples. Charge-Detection MassSpectrometry (CDMS) is a unique technique used to measure mass distribution. ${ }^{17,} 18$ It extends the limit of other MS devices by measuring molar weights in the range of mega- to gigadalton thus allowing the study of larger systems such as viruses, bio-particles and even NP assemblies. ${ }^{19-23}$ Experiments were performed on a custom-built charge detection mass spectrometer with an electrospray ionisation (ESI) source (see details in Supplementary Information and Figs S1 and S2). This instrument is described in detail elsewhere. ${ }^{17,24}$ The charge detection device was used in a single pass mode at the single particle level. Since graphene oxide has chemically reactive oxygen-containing groups, including carboxylic acid groups, epoxy and hydroxy groups, it is soluble in water and organic solvents and may be easily charged by the electrospray process. Charge detection mass spectrometry measures the mass of individual electro-sprayed ions thanks to the independent measurement of the $\mathrm{m} / \mathrm{z}$ ratio and the charge $\mathrm{z}$ for thousands of individual ions. Fig. S3 in the supplementary information displays the raw data obtained by CDMS plotted in a twodimensional $z$ vs $m$ graph. These $(z-m)$ maps illustrate the unique type of data that CDMS can provide. Mass histograms are built from the collection of a statistically relevant number of

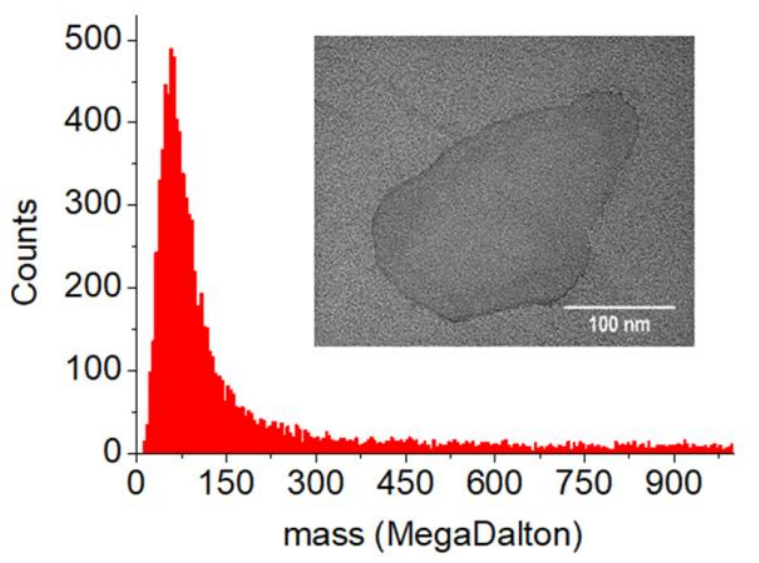

single mass measurements for each sample (>5000 typically).

Figure 2: Mass histograms for graphene oxide samples obtained from charge detection mass spectrometry (CDMS) measurements. Inset. Selected TEM micrograph of a graphene oxide sheet.
A mass histogram from 2D graphene oxide sheets is depicted in Fig. 2 and shows an average mass of $70 \mathrm{MDa}$. The mass distribution is quite broad extending from $\sim 10 \mathrm{MDa}$ to $\sim 1 \mathrm{GDa}$, illustrating the large polydispersity in GO samples obtained by the modified Hummers' method. ${ }^{25}$ The average mass can be converted to an average size assuming a crude squared 2D form for the $\mathrm{GO}$ sheets. Knowing the atomic density of graphene, i.e. 38 atom $/ \mathrm{nm}^{2}$, thus $2 \mathrm{D}$ GO samples exhibit an average size of $\sim 390 \mathrm{~nm}$ in fair agreement with the dimensions observed for selected GO samples by TEM measurements (inset of Fig. 2 and Fig. S4). We would like to emphasize that the accurate and direct measurement of GO samples molar mass allows for a quantitative determination of their concentration, an essential requisite for absolute measurements of hyperpolarizability. Also, CDMS measurements allow us to have access to the entire distributions of all samples, which is not realistic with partial sampling by electron-based microscopy. Fig. S5 shows the C1s signal of the prepared graphite oxide powder obtained by $x$-ray photoelectron spectrometer (XPS). This signal was fitted by four components: C-C/C-H (67\%,284.4 eV), C-O (18\%, $286.5 \mathrm{eV}), \mathrm{C}=\mathrm{O}$ $(9.0 \%, 287.7 \mathrm{eV})$ and $\mathrm{O}=\mathrm{C}-\mathrm{OH}(6.0 \%, 288.8 \mathrm{eV})$ (see Table S2). The estimated C/O ratio is $\sim 2.6$ (see table S1). Also SAED pattern from GO sheets leads to a spacing for GO planes of $0.22 \mathrm{~nm}$ (see Fig. S4) in accordance with previous studies. ${ }^{26}$

The first hyperpolarizability of the as-prepared GO samples was obtained using the HRS technique (see details in Supplementary Information and Fig. S2). ${ }^{27}$ The HRS intensity was recorded for several concentrations of the NPs dispersed in aqueous solutions (see Fig. 3a and Fig. S6) and short-range spectra were recorded on both sides of the HRS wavelength. The absolute concentration of GO was obtained by knowledge of the average molar mass of the sample (e.g. $\left.7010^{6} \mathrm{~g} / \mathrm{mol}\right)$. For the estimation of solubility values for GO in water, UV-vis spectroscopy was used. Using suspensions left over for more than 2 weeks, dispersion of $\mathrm{GO}$ (in $\mathrm{g} / \mathrm{l}$ ) in water using the calibration line built by measuring the absorbance at $660 \mathrm{~nm}$ of $\mathrm{GO}$ solutions with different low concentrations was obtained. ${ }^{28}$ The linear dependence of the absorbance with concentration is given in Fig. S7. A final dispersion of $\mathrm{GO}$ (in $\mathrm{g} / \mathrm{l}$ ) in water was found to be $8.07 \mathrm{mg} / \mathrm{L}$. Thus the initial concentration of the $\mathrm{GO}$ aqueous solution was $115 \mathrm{pM}$. The subtraction of the background coming from TPEF was performed by fitting the narrow band background spectra with a Gaussian function for the HRS line superposed on a linear function of the wavelength accounting for the broadband luminescence background. This subtraction procedure is allowed since the two processes, photoluminescence and HRS, are incoherent. The HRS intensity is then given by $:^{29}$

$$
\frac{I_{H R S}}{I_{H R S}^{w}}=\frac{\left\langle N_{w} \beta_{w}^{2}+N \beta^{2}\right\rangle}{\left\langle N_{w} \beta_{w}^{2}\right\rangle}=1+b^{\prime} N\left\langle\beta^{2}\right\rangle
$$

where the subscript $w$ stands for water, the reference solvent used in this experiment. Losses due to absorbance at the fundamental and harmonic frequencies were determined from separate UV-visible absorption measurements (see Fig. S8) and all data were corrected prior to the analysis. The first 
hyperpolarizability values $\langle\beta>$ in esu units at $800 \mathrm{~nm}$ laser excitation was found to be $(1,36+/-0,15) \times 10^{-25} \mathrm{esu}$. This value reported here for $\mathrm{GO}$ sheets is in the same order of magnitude than that reported for 2D WS 2 monolayers under $1064 \mathrm{~nm}$ laser irradiation using paranitroaniline as the external reference. ${ }^{30,} 31$ However, the SHG signal in $2 \mathrm{D} \mathrm{WS}_{2}$ monolayers may find a different origin as compared to the SHG signal in $\mathrm{GO}$ because $\mathrm{WS}_{2}$ monolayers lack inversion symmetry and have therefore a non-vanishing first hyperpolarizability. Further analysis through DFT calculations have indicated that this large first hyperpolarizability in $\mathrm{WS}_{2}$ monolayers is due to resonance enhancement as well as the presence of a large joint density of states. $^{32}$ For GO sheets, the presence of reactive oxygencontaining groups, including carboxylic acid groups at the edges of GO and epoxy and hydroxy groups on the basal planes may be key factors leading to an enhanced first hyperpolarizability, as reported in this work. To go further in determining the origin of this nonlinearity, the SHG response of the GO samples was recorded as a function of the fundamental input beam polarization angle. The polar plots exhibit apurely dipolar contribution as evidenced by a perfect two-lobe pattern (see Fig. S9). Despite the size of the GO flakes, non negligible before the fundamental $800 \mathrm{~nm}$ wavelength, it is surprising that no retardation is observed. This result rather suggests a response stemming from the whole flake volume owing to a broken inversion symmetry rather than a response stemming from the edges only. Nevertheless, the sources to the nonlinearity seems

to be

a)

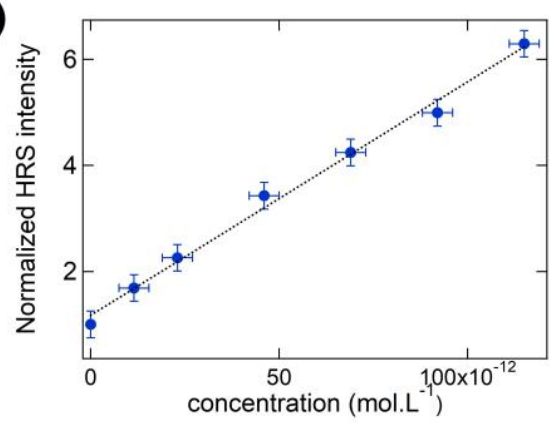

b)

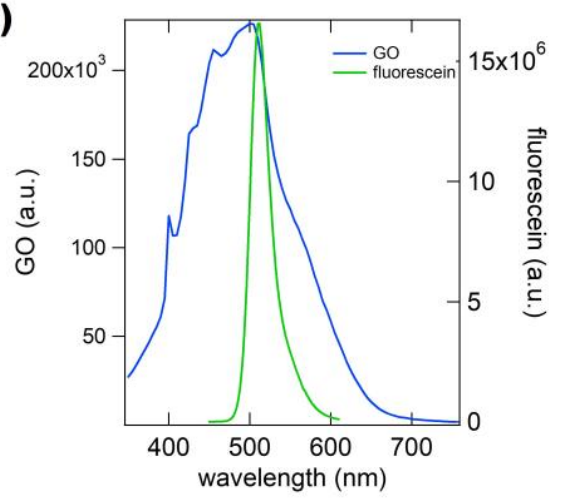

Figure 3: (a) Plot of the HRS intensity of for GO as a function of concentration. The continuous lines correspond to the linear adjustment to eq (1). (b) multiphoton excited fluorescence spectrum of $\mathrm{GO}$ in aqueous solution ( $115 \mathrm{pM}$, blue curve) with excitation at $800 \mathrm{~nm}$. The TPEF spectrum of fluorescein ( $10 \mu \mathrm{M}$ in water) is also given (green curve). The peak at $400 \mathrm{~nm}$ corresponds to SHG line.

distributed in orientation over the whole volume because the depolarization ratio, about $1 / 2$, deviates from that of a single axis system. Finally, these conclusions must beconsidered in light of the flexibility of the GO flakes in solution and their possible wrinkling or wrapping, ${ }^{33}$ geometries allowed by the observed experimental data. These geometries may lead to the appearance of non-negligible tensor elements otherwise forbidden by symmetry rules. To this end, in order to confirm the possibility of wrinkling and wrapping of GO flakes, TEM analysis was performed. Interestingly, the wrinkled and wrapped (folded) features of the GO flakes was clearly evidenced from the TEM images (see Fig. S10).

In addition to the characteristic monochromatic SHG line observed at $400 \mathrm{~nm}$, emergence of a strong background is also observed at wavelengths shorter and longer than $400 \mathrm{~nm}$. This background is the signature of a multiphoton excited fluorescence signal. ${ }^{34}$ In particular, the appearance of the fluorescence at wavelengths shorter than $400 \mathrm{~nm}$ indicates that at least three photons are required in the excitation step. Fig. $3 \mathrm{~b}$ presents the MPEF spectrum of GO samples recorded following a laser excitation at $800 \mathrm{~nm}$. A broadband in the visible range between 350 and $700 \mathrm{~nm}$ and centred at about 500 $\mathrm{nm}$ was observed. The MPEF spectrum is similar to the one reported for aptamer conjugated graphene oxide. ${ }^{15}$ The origin of MPEF signal for pure GO and GO composites may be due to several highly efficient intramolecular charge transfers between large $\pi$-conjugated systems and the strong electron donating moieties carboxy and hydroxyl of water soluble graphene oxide sheets. Indeed, it has been shown by a computational approach that ideal graphene sheets decorated with functional groups such as hydroxyl, epoxy, carboxyl, or an atomic vacancy, which create distortions in the aromatic rings, cause a broad absorption spectra and also result in the absorption in the lower energy regions. ${ }^{35}$

In summary, in this communication we report a nonlinear optical study of 2D graphene oxide sheets. By an accurate characterization of the as-synthesized graphene oxide sheets, and by measuring their molar mass distribution, we have been able to determine for the first time their first hyperpolarizability at $800 \mathrm{~nm}$ laser excitation. A large value of hyperpolarizability (e.g. $\left.(1,36+/-0,15) \times 10^{-25} \mathrm{esu}\right)$ is measured. This may open new avenues to applications of graphene-oxide based nanomaterials in second-order nonlinear optics. Furthermore, these data represent benchmarks for NLO properties of 2D graphene oxide sheets and shall be used in the future to understand the additional effects on the NLO properties of nanoparticles decorated 2D graphene oxide platforms. More work is needed in this area and is currently underway in our lab.

\section{Conflicts of interest}

There are no conflicts to declare.

\section{Acknowledgments}

The authors would like to thank Céline Brunon from Science et Surface (http://www.science-et-surface.fr) for XPS spectra and Nicholas Blanchard (iLM) for TEM measurements. This research was partially supported by the project STIM - REI, Contract Number: KK.01.1.1.01.0003, funded by the European 
Union through the European Regional Development Fund the Operational Programme Competitiveness and Cohesion 2014-2020 (KK.01.1.1.01). One of the authors NK gratefully acknowledges the CNRS Visiting Professorship with Institut Lumière Matière, UMR 5306 CNRS, Université Claude Bernard Lyon 1, France. The authors PV, ST and NK also acknowledge DST- Nano Mission, Govt. Of India for projects funding.

\section{Notes and references}

1. G. G. Naumis, S. Barraza-Lopez, M. Oliva-Leyva and H. Terrones, Reports on Progress in Physics, 2017, 80, 096501.

2. K. S. Novoselov, S. V. Morozov, T. M. G. Mohinddin, L. A. Ponomarenko, D. C. Elias, R. Yang, I. I. Barbolina, P. Blake, T. J. Booth, D. Jiang, J. Giesbers, E. W. Hill and A. K. Geim, physica status solidi (b), 2007, 244, 4106-4111.

3. E. Hendry, P. J. Hale, J. Moger, A. K. Savchenko and S. A. Mikhailov, Physical Review Letters, 2010, 105, 097401.

4. Q. Bao, H. Zhang, Y. Wang, Z. Ni, Y. Yan, Z. X. Shen, K. P. Loh and D. Y. Tang, Advanced Functional Materials, 2009, 19, 3077-3083.

5. D. R. Dreyer, S. Park, C. W. Bielawski and R. S. Ruoff, Chemical Society Reviews, 2010, 39, 228-240.

6. S. Wang, Y. Dong, C. He, Y. Gao, N. Jia, Z. Chen and W. Song, RSC Advances, 2017, 7, 53643-53652.

7. Z.-B. Liu, X. Zhao, X.-L. Zhang, X.-Q. Yan, Y.-P. Wu, Y.-S. Chen and J.-G. Tian, The Journal of Physical Chemistry Letters, 2011, 2, 1972-1977.

8. Z. Liu, Y. Wang, X. Zhang, Y. Xu, Y. Chen and J. Tian, Applied Physics Letters, 2009, 94, 021902.

9. J. W. You, S. R. Bongu, Q. Bao and N. C. Panoiu, Journal, 2018, 8, 63.

10. N. Vermeulen and S. Palomba, APL Photonics, 2019, 4, 060402.

11. Q. Mei, B. Liu, G. Han, R. Liu, M.-Y. Han and Z. Zhang, Advanced Science, 2019, 6, 1900855.

12. J. Shang, L. Ma, J. Li, W. Ai, T. Yu and G. G. Gurzadyan, Scientific Reports, 2012, 2, 792.

13. H. R. Thomas, C. Vallés, R. J. Young, I. A. Kinloch, N. R. Wilson and J. P. Rourke, Journal of Materials Chemistry C, 2013, 1, 338-342.

14. L. Zhao, J. Chen, X. He, X. Yu, S. Yan, S. Zhang, H. Pan and J. Xu, Chemical Physics, 2018, 508, 1-6.

15. A. Pramanik, Z. Fan, S. R. Chavva, S. S. Sinha and P. C. Ray, Scientific Reports, 2014, 4, 6090.

16. P. Nancy, A. K. Nair, R. Antoine, S. Thomas and N. Kalarikkal, Nanomaterials, 2019, 9, 1201.

17. R. Antoine, Rapid Commun Mass Spectrom. 2020, e8539. https://doi.org/10.1002/rcm.8539.

18. D. Z. Keifer and M. F. Jarrold, Mass Spec Rev. 2016, 36, 715-733. doi:10.1002/mas.21495.

19. T. Doussineau, C. Mathevon, L. Altamura, C. Vendrely, P. Dugourd, V. Forge and R. Antoine, Angewandte Chemie International Edition, 2016, 55, 2340-2344.

20. H. Fakhoury, M. Perić, F. Bertorelle, P. Dugourd, x. dagany, I. Russier-Antoine, P.-F. Brevet, V. BonacicKoutecky and R. Antoine, Phys. Chem. Chem. Phys., 2019, 21, 12091-12099

21. T. Doussineau, A. Désert, O. Lambert, J.-C. Taveau, M. Lansalot, P. Dugourd, E. Bourgeat-Lami, S. Ravaine, E.
Duguet and R. Antoine, The Journal of Physical Chemistry C, 2015, 119, 10844-10849

22. D. Z. Keifer, T. Motwani, C. M. Teschke and M. F. Jarrold, Rapid Communications in Mass Spectrometry, 2016, 30, 1957-1962.

23. V. U. Weiss, R. Pogan, S. Zoratto, K. M. Bond, P. Boulanger, M. F. Jarrold, N. Lyktey, D. Pahl, N. Puffler, M. Schelhaas, E. Selivanovitch, C. Uetrecht and G. Allmaier, Analytical and Bioanalytical Chemistry, 2019, 411, 59515962.

24. T. Doussineau, M. Kerleroux, X. Dagany, C. Clavier, M. Barbaire, J. Maurelli, R. Antoine and P. Dugourd, Rapid Communications in Mass Spectrometry 2011, 25, 617.

25. R. T. M. Ahmad, T.-Z. Shen, A. R. Masud, T. K. Ekanayaka, B. Lee and J.-K. Song, Langmuir, 2016, 32, 13458-13463.

26. N. R. Wilson, P. A. Pandey, R. Beanland, R. J. Young, I. A. Kinloch, L. Gong, Z. Liu, K. Suenaga, J. P. Rourke, S. J. York and J. Sloan, ACS Nano, 2009, 3, 2547-2556.

27. T. Verbiest, K. Clays, C. Samyn, J. Wolff, D. Reinhoudt and A. Persoons, Journal of the American Chemical Society, 1994, 116, 9320-9323.

28. D. Konios, M. M. Stylianakis, E. Stratakis and E. Kymakis, Journal of Colloid and Interface Science, 2014, 430, 108112.

29. R. Antoine and V. Bonacic-Koutecky, Liganded silver and gold quantum clusters. Towards a new class of nonlinear optical nanomaterials, Springer, Cham, 2018.

30. G. T. Forcherio, J. Riporto, J. R. Dunklin, Y. Mugnier, R. L. Dantec, L. Bonacina and D. K. Roper, Opt. Lett., 2017, 42, 5018-5021.

31. G. T. Forcherio, J. Riporto, J. R. Dunklin, Y. Mugnier, R. Le Dantec, L. Bonacina and D. K. Roper, Opt. Lett., 2018, 43, 2400-2401.

32. C. Janisch, Y. Wang, D. Ma, N. Mehta, A. L. Elías, N. PereaLópez, M. Terrones, V. Crespi and Z. Liu, Scientific Reports, 2014, 4, 5530.

33. R. A. Soler-Crespo, W. Gao, P. Xiao, X. Wei, J. T. Paci, G. Henkelman and H. D. Espinosa, The Journal of Physical Chemistry Letters, 2016, 7, 2702-2707.

34. J. Qian, D. Wang, F.-H. Cai, W. Xi, L. Peng, Z.-F. Zhu, H. He, M.-L. Hu and S. He, Angewandte Chemie International Edition, 2012, 51, 10570-10575.

35. C.-T. Chien, S.-S. Li, W.-J. Lai, Y.-C. Yeh, H.-A. Chen, I.-S Chen, L.-C. Chen, K.-H. Chen, T. Nemoto, S. Isoda, M. Chen, T. Fujita, G. Eda, H. Yamaguchi, M. Chhowalla and C.-W. Chen, Angewandte Chemie International Edition, 2012, 51, 6662-6666. 